\title{
PERCUTANEOUS CAROTID ANGIOGRAPHY
}

\section{A TEAM TECHNIQUE}

\author{
WITH A REPORT OF THE RESULTS IN SEVENTY CASES \\ BY
}

\author{
M. WILkinson, J. B. STANTON, D. P. JONES, and J. M. K. SPALDing \\ From the Maida Vale Hospital for Nervous Diseases, London
}

Percutaneous carotid angiography was used successfully by Egas Moniz (1931), Loman and Myerson (1936), and Shimidzu (1937), but was first perfected as a routine investigation by Engeset (1944) and Lindgren (1947). Lindgren's technique was studied in Stockholm by Bull, who subsequently introduced the method in this country. This paper records the results of a series of cases in which carotid angiography has been performed by a team using a modification of methods described by these writers.

\section{Technique}

Anæesthesia and Preparation.-Paraldehyde, $10 \mathrm{ml}$. intramuscularly, is given as a routine premedication one hour before angiography. For children, rectal avertin in basal anæsthetic dosage is used. Intravenous thiopentone anæsthesia was used for ten patients, but despite its apparent convenience it should be used with caution as it adds the risks of general anæsthesia to the procedure. Green and Arana (1948), however, used general anæsthesia in all their cases.

Apparatus.-A short-bevelled 17-gauge needle $9 \mathrm{~cm}$. long is used for injecting the carotid artery in adults, and a smaller needle is used for children; these needles are sharpened each time they are used. The needle is attached by a junction to pressure tubing $20 \mathrm{~cm}$. long, in which there is a 4-cm. length of glass tubing (Fig. 1). Standard record junctions are used and are firmly bound to the pressure tubing with linen thread. Other requirements are a hypodermic syringe for local anæsthesia, three 20-ml. Record syringes for saline, and a $10-\mathrm{ml}$. syringe for the contrast medium which is "Uriodone" in 35 and 50 per cent. solutions. The syringes must fit well and run smoothly, and normal saline solution, heated to body temperature, should be available in ample quantity.

Angiography.-The patient lies supine with his neck extended and his head raised from the Schonander table by a pad and steadied by a head-band. His left shoulder is in close contact with the serial cassette holder. The $x$-ray tube is placed in position for a lateral view of the skull, and a preliminary radiograph is taken. A rubber sheet and sterile towels cover the patient's chest. The first member of the team (the "operator") standing on the right of the patient, cleans the skin of the neck with spirit, and raising a bleb of local anæsthetic at the intended site of puncture, injects a minimal amount subcutaneously. In most cases the internal carotid artery is punctured at the point where its pulsation is most easily felt. This is usually at the level of the upper border of the thyroid cartilage, where the artery is comparatively superficial in the carotid triangle, lateral to the external carotid artery, and covered by skin, platysma, and deep cervical fascia. If, however, a common carotid angiogram is required, the needle is introduced at the point of maximal pulsation just above the clavicle. The second member of the team (the " assistant") assembles the needle and tubing and fills them with warm normal saline solution from a 20-ml. syringe. The operator inserts the needle through the bleb of local anæsthetic, and when the needle has penetrated the skin the assistant disconnects the syringe. The operator steadies the artery between the second and third fingers of the left hand and inserts the needle. When the needle is in the lumen of the artery, blood rises at once and can be seen in the glass tubing. The artery is sometimes occluded by the pressure of the needle, and blood only appears in the glass tubing when the needle is slightly withdrawn. When a successful puncture has been made, the assistant again connects the $20-\mathrm{ml}$. syringe of saline to the tubing and starts to inject at a rate of 15 to $20 \mathrm{ml}$. per minute. From this time the operator's sole duties are to hold the needle steady in position and to compress the contralateral carotid artery when filling across the Circle of Willis is required.

A lead-rubber screen is pulled down over the neck of the patient to protect the hands of the operator and assistant during exposure, and the $x$-ray machine is switched on. When all is ready, the assistant exchanges the syringe of saline solution for a $10-\mathrm{ml}$. syringe containing 35 per cent. Uriodone. $\mathrm{He}$ injects the whole $10 \mathrm{ml}$. of contrast solution in three seconds, and when the syringe is still one-third full he calls " shoot" to the radiographer who takes the first exposure $(0.75 \mathrm{sec}$, $70 \mathrm{kV}$, and $100 \mathrm{ma}$.). When the exposure is completed, the radiographer calls "pull" to the third member of the team, who removes the exposed film from the serial cassette holder, and calls "shoot" for the second exposure. By a similar routine the second film is 
removed and the third exposed. The first picture, taken two seconds after the injection is started, gives an arteriogram, and the further exposures at $3 \cdot 25$ and 4.5 secs. give early and late phlebograms. Between five and six seconds elapse from the beginning of the injection to the end of the third exposure.

The third member of the team inspects the radiographs, which are developed immediately. In the meantime, the assistant perfuses the artery with normal saline while the $x$-ray apparatus is set up for taking an antero-posterior view of the skull. The pad is removed from under the patient's head, and with great care his head is slightly flexed. This is done by the radiographer under the supervision of the third member of the team. Antero-posterior angiograms are then taken, the routine being similar to that for the lateral view with the following exceptions : the contrast solution is $42 \frac{1}{2}$ per cent. Uriodone, made by mixing equal volumes of the 35 and 50 per cent. solutions, the exposure is for $1 \mathrm{sec}$. at $67 \mathrm{kV}$ and $100 \mathrm{ma}$.; and only two radiographs are taken. A second series of antero-posterior angiograms may be made with compression of the contralateral carotid artery where this is indicated to fill the anterior and middle cerebral vessels on both sides (Engeset and Kristiansen, 1948). Stereoscopic views may be obtained in lateral and antero-posterior planes by taking two series of angiograms with a $6^{\circ}$ shift of the $x$-ray tube before the second series.

The third member of the team examines all the radiographs and reports if further angiograms are required. When a satisfactory series of radiographs has been obtained, the needle is removed and firm pressure exerted on the puncture site until all oozing has stopped. Elastoplast is then applied over a piece of dry sterile gauze and is removed after twelve hours.

This technique requires a team of three with the assistance of a radiographer and a nurse. Each of the three members of the team is familiar with every position in the team and takes it in turn to perform the puncture. While angiography can only be performed by a team, it is our experience that a successful puncture will be obtained by one operator soon or not at all, and therefore if the first operator is not successful in a few minutes his place is taken by another member of the team, and if necessary the third member is called upon.

\section{Results}

The material consists of seventy angiograms performed on sixty-eight patients whose ages ranged from nine to seventy-two years. Good filling of the cerebral vessels was obtained in sixtysix cases. In fifty cases both lateral and anteroposterior views were good, and in sixteen cases the lateral views were satisfactory but no anteroposterior views were taken. In some cases this was because the diagnosis could be made from the lateral views alone, but in the early cases adequate $x$-ray apparatus was not available for taking good quality antero-posterior angiograms. In thirteen cases it was necessary to make more than one attempt before satisfactory angiograms could bê obtained. In only four cases was the examinatio completely unsuccessful, and in three of these only one attempt could be made. The results of the investigation in the sixty-six successful cases are given in the Table.

TABLE

RESULTS OF SIXTY-SIX ANGIOGRAMS

\begin{tabular}{|c|c|c|c|}
\hline \multirow{2}{*}{$\begin{array}{l}\text { Clinical } \\
\text { diagnosis }\end{array}$} & \multirow{2}{*}{$\begin{array}{l}\text { Number } \\
\text { in which } \\
\text { angio- } \\
\text { graphy } \\
\text { performed }\end{array}$} & \multicolumn{2}{|c|}{$\begin{array}{c}\text { Angiographic } \\
\text { appearance }\end{array}$} \\
\hline & & $\begin{array}{l}\text { Patho- } \\
\text { logical }\end{array}$ & Norma \\
\hline \multirow{6}{*}{ 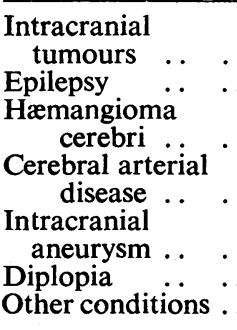 } & 16 & 12 & 4 \\
\hline & 16 & 1 & 15 \\
\hline & 7 & 7 & 0 \\
\hline & 5 & 2 & 3 \\
\hline & 5 & 2 & 3 \\
\hline & $\begin{array}{r}3 \\
14\end{array}$ & $\begin{array}{l}0 \\
2\end{array}$ & $\begin{array}{r}3 \\
12\end{array}$ \\
\hline \multirow[t]{2}{*}{ Totals } & 66 & 26 & 40 \\
\hline & Case Mate & & \\
\hline
\end{tabular}

18586) was aged 36 years. At the age of 12 years, attee a minor head injury, he developed right hemiparesis ance hemiparæsthesiæ with flashes of light in the right visuat half-field. This lasted for a month and since then he hao been liable to transient attacks of the same sort, oftep associated with difficulty in speaking. At the age of 38 he began to have Jacksonian attacks starting in the righ? hand. Two and a half months before admission he hae a probable subarachnoid hæmorrhage. His positiv $\overrightarrow{5}$ physical signs were a loud systolic bruit in the left parieta $\$$ region, and some limitation of the right visual half-fieldBlood pressure was $150 / 75 \mathrm{~mm}$. $\mathrm{Hg}$, and the apex bea was displaced one inch laterally (Figs. 2a and 2b).

Case 2. Aneurysm of Internal Carotid Artery.-Thi was a man (No. 17366) aged 53 years. Five monthisbefore admission the vision of the left eye became blurred?. and two weeks before admission he developed pain and swelling of the left eyeball and orbit. He was diagnosec5 as having glaucoma, and the lens was removed. Four days after operation he awoke with a complete right third nerve palsy and occipital headache radiating overp the right side of the head to the front. Pain ceased in a. week but the palsy persisted (Fig. 3).

Case 3. Thrombosis of Middle Cerebral Artery.-This̆ was a man (No. 19631) aged 44 years. Two years before admission he had three epileptic fits following a "stroke " 
which left him with a left hemiparesis. The fits appeared to begin in the left hand. When he was examined he was found to have left hemiparesis with impairment of cortical sensory function over the left side. Blood pressure was $180 / 100 \mathrm{~mm}$. $\mathrm{Hg}$ (Fig. 4).

\section{Complications}

The complications described by previous writers include hæmatoma of the neck, thrombosis of the arterial wall at the site of puncture, cerebral embolus, recurrent laryngeal palsy, cervical sympathetic palsy, and iodine sensitivity reactions.

The following were the complications encountered in this series of cases :

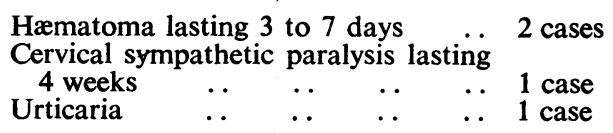

Most patients complained of slight soreness at the site of puncture for twenty-four hours after injection, but if digital compression is applied until all oozing has stopped as soon as the needle is withdrawn, there is no danger that a large hæmatoma will form after the patient has returned to the ward. There were a few patients who developed a slight swelling at the site of puncture which did not require special treatment and subsided in two or three days. In all cases in which a second attempt at puncture was necessary, it was found that this could be done within a few days.

One patient, who was known to have had epileptic attacks for several years, had a fit during the investigation; another patient vomited. In both cases the investigation was continued after a short interval and satisfactory radiographs were obtained without ill effects.

There was one case of cervical sympathetic paralysis which cleared up spontaneously after four weeks.

One patient (Case 1, above) developed slight weakness of his right hand two days after angiography. It was thought that this was caused by progression of his lesion (a large angioma) rather than by the angiography.

On two occasions angiography was performed on patients who were severely ill and stuporose. One patient, who had a large subdural hæmatoma, died five days later.' The deterioration in his condition was gradual and did not appear to have been accelerated by the investigation. In the other patient angiography was performed directly after pneumoencephalography when the patient was comatose. This patient had gross generalized cortical atrophy, and died six days later from bronchopneumonia.

\section{Discussion}

Using the team technique described above for percutaneous angiography, exposure of the artery at operation was not employed in this series of cases. The complications encountered were also few, and those patients on whom both pneumoencephalography and angiography was performed usually said that the latter was the less unpleasant.

Paraldehyde was used for premedication as it was found that some sedation was desirable. General anæsthesia, in our opinion, is unnecessary in most cases and may even be an added risk.

As a rule the internal carotid artery should be punctured, since better contrast is then obtained with a smaller volume of Uriodone. If, however, there is an' indication for filling branches of the external carotid artery, as in a case of suspected meningioma, this should be done by puncture of the common carotid artery low in the neck.

Uriodone has been used as the contrast material in all cases, in concentrations up to 70 per cent., but it has been found that good angiograms can be obtained by using 35 per cent. solution in the lateral view and $42 \frac{1}{2}$ per cent. solution in the anteroposterior view. The maximum amount of Uriodone injected in any one patient in this series was $40 \mathrm{ml}$. of 70 per cent. solution; there were no ill effects. All patients were tested for sensitivity to Uriodone by instilling two drops of 35 per cent. solution into the conjunctival sac on the day before angiography was to be performed. One patient developed urticaria of the face and neck during angiography, although he had given no reaction to the Uriodone sensitivity test.

Injection of the Uriodone causes a transitory burning sensation in the area of distribution of the vessel punctured. If the common carotid artery has been injected the pain is felt in the teeth, lower jaw, and ear, and if the internal carotid artery is punctured the pain is felt behind the eye. The patient should be warned of these symptoms immediately before injection so that he will not move during the exposures. There is usually flushing of the face and dilatation of the ipsilateral pupil. These symptoms and signs confirm that the contrast material has been satisfactorily distributed through the branches of the artery.

It is most important that neither saline nor Uriodone should be injected unless the needle is in the lumen of the artery. The needle does not become blocked, as a rule, except by clotted blood from puncture of a vein. If it is suspected that this has occurred, the needle should be withdrawn and flushed clear.

Although as a general rule gross hypertension is 
regarded as a contraindication to angiography, this investigation was done without ill effect on a patient with a blood pressure of $240 / 140 \mathrm{~mm}$. $\mathrm{Hg}$.

The complete operation from the injection of local anæsthetic to the removal of the needle usually lasts half an hour, but in one case, in which two sets of lateral and two sets of antero-posterior radiographs were taken, the duration was twenty minutes.

\section{Summary}

1. The development of the percutaneous method of carotid angiography is reviewed.

2. A simple technique for a team of three assisted by a nurse and a radiographer is described. Details found to be important are emphasized.

3. The results obtained in seventy angiograms are reported, and three illustrative angiograms with case histories are included.
4. The complications encountered in the series are listed.

We express our gratitude to Dr. W. Russell Brain for his encouragement in the preparation of this report, and to Dr. J. W. D. Bull for his helpful criticism and permission to publish the radiographs.

\section{REFERENCES}

Engeset, A. (1944). Acta. Radiol., Stockholm., Suppl. 56. - and Kristiansen, K. (1948). In "Modern Trends in Diagnostic Radiology." London. Pp. 352.

Green, J. R., and Arana, R. (1948). Amer. J. Rontgen., $59,617$.

Lindgren, E. (1947). 'Brit. J. Radiol., n.s., 20, 326.

Loman, J., and Myerson, A. (1936). 'Amer. J. Rontgen., $35,188$.

Moniz, Egas (1931). “Diagnostic des tumeures Cere- $\bigcirc$ brales et Epreuve de l'Encephalographie Arterielle. œ Paris,

Shimidzu, K. (1937). Arch. klin. Chir., 188, 295.

Turnbull, F. (1939). Amer. J. Rontgen., 41, 166. 